Pacific Journal of Mathematics

THE SPACE OF REAL PARTS OF A FUNCTION ALGEBRa 


\section{THE SPACE OF REAL PARTS OF A FUNCTION ALGEBRA}

\section{JOHN WERMER}

1. Introduction. Let $X$ be a compact Hausdorff space and $C(X)$ the algebra of all complex-valued continuous functions on $X$. We consider a closed subalgebra $A$ of $C(X)$ which separates the points of $X$ and contains the constants. We call $A$ "a function algebra on $X$ ".

Let Re $A$ denote the class of functions $u$ real and continuous on $X$ such that for some $f$ in $A, u=\operatorname{Re} f$. Then $R e A$ is a real vector space of real continuous functions on $X$. What more can be said about $\operatorname{Re} A$ ?

In [3] it was shown that $R e A$ cannot be closed under uniform convergence on $X$ unless $A=C(X)$. Here we shall show that $\operatorname{Re} A$ cannot be closed under multiplication unless $A=C(X)$. In other words:

\section{Theorem 1: If Re $A$ is a ring, then $A=C(X)$.}

This result was conjectured by K. Hoffman. As a corollary one gets the existence of a continuous function $u$ on the unit circle having the following property: $u$ has a continuous conjugate function (in the sense of Fourier theory) whereas $u^{2}$ does not. For we may take for $A$ the algebra of continuous functions on the circle which extend analytically to the unit disk. Then $\operatorname{Re} A$ is the class of all functions which are continuous and have continuous conjugates. But $A \neq C(X)$. Hence by Theorem 1, Re $A$ is not a ring, hence not closed under squaring, and so the desired $u$ exists.

The existence of such a $u$ had been shown in 1961 by J. P. Kahane (unpublished). It should be noted that if a function $u$ is sufficiently smooth to have an absolutely convergent Fourier series, then $u^{2}$ does also, and hence $u^{2}$ does have a continuous conjugate.

2. The antisymmetric case. In this section we assume that $A$ is anti-symmetric, i.e. contains no real functions except constants, and prove Theorem 1 under this hypothesis. This amounts to proving:

THEOREM 1'. Let $A$ be anti-symmetric and let Re $A$ form a ring. Then $X$ consists of a single point.

Assume $X$ contains a point $x_{0}$ and another point $x_{1}$. We must deduce a contradiction. Fix $u$ in $R e A$. Then (because of antisymmetry),

Received October 1, 1962. The author is a fellow of the Alfred P. Sloan Foundation. 
there exists exactly one $f$ in $A$ with $u=R e f$ and $\operatorname{Im} f\left(x_{0}\right)=0$. The map: $u$ into $f$ is now a real-linear map of $R e A$ into $A$ which is oneto-one. We can then norm $R e A$ by the norm $N$ :

$$
N(u)=\max _{x}|f|=\|f\| \text {. }
$$

In this norm Re $A$ is then evidently a real Banach space. By standard application of the closed graph theorem, we have

Lemma 1. There exists a constant $K$ such that for all $u, u^{\prime}$ in Re A

$$
N\left(u \cdot u^{\prime}\right) \leqq K \cdot N(u) \cdot N\left(u^{\prime}\right)
$$

Lemma 2. If $p$ lies in $\operatorname{Re} A$ and $p>0$ on $X$, then $\log p$ is in Re A.

Proof. Let $S$ be the class of functions $u+i u^{\prime}$ with $u$ and $u^{\prime}$ in $R e A$. Then $S$ is an algebra of complex-valued functions on $X$ containing $A$ as a subalgebra and closed under complex conjugation. Define $N\left(u+i u^{\prime}\right)=N(u)+N\left(u^{\prime}\right)$ and $\|f\|^{\prime}=\sup _{\theta} N\left(e^{i \theta} f\right)$ for all $f$ in $S$. Then $S$ is a (complex) Banach space under \|\|$^{\prime}$ as norm and also $\|f \cdot g\|^{\prime} \leqq K\|f\|^{\prime} \cdot\|g\|^{\prime}$. Hence $S$ is a Banach algebra under a norm equivalent to \|\|$^{\prime}$.

Let $M_{S}$ denote the space of homomorphisms of $S$ into the complex numbers and $M_{A}$ be the corresponding space for $A$. Fix $m$ in $M_{S}$. Restricted to $A, m$ is an element $\sigma$ of $M_{A}$. Also the map: $f$ into $\overline{m(\bar{f})}$, restricted to $A$, is an element $\tau$ of $M_{A}$. Since $p$ lies in $R e A$, we can find some $r$ in $A$ such that

$$
p=\frac{1}{2}(r+\bar{r}) \quad \text { whence } m(p)=\frac{1}{2}(m(r)+m(\bar{r})),
$$

or

$$
m(p)=\frac{1}{2}(\sigma(r)+\overline{\tau(r)}) .
$$

By hypothesis, $R$ e $r=p>0$ on $X$. Hence by a well-known property of function algebras, $R e \beta(r)>0$ for all $\beta$ in $M_{A}$. In particular $\operatorname{Re} \sigma(r)>0$ and $\operatorname{Re} \tau(r)>0$. Hence $\operatorname{Re} m(p)>0$.

Since this holds for all $m$ in $M_{s}$, we can, by the general theory of Banach algebras, apply to $p$ any function analytic in the right half-plane and still stay in the algebra $S$. Hence $\log p$ is an element of $S$, and, being real valued, of $R e A$.

Let now $K^{*}$ be any positive number. Choose $g$ in $A$ with $g\left(x_{0}\right)=0$ 
and $\|g\|=1$. Let $a$ be some point in $X$ where $|g(a)|=1$. Next choose $\varphi$ analytic in $|z|<1$, continuous in $|z| \leqq 1$, such that $0<R e \varphi \leqq$ 1 in $|z| \leqq 1, \operatorname{Im} \varphi(0)=0$ and $\operatorname{Im} \varphi(g(a)) \geqq K^{*}$. Put $f=\varphi(g)$. Then $f$ belongs to $A$ and we have:

$$
0<R e f \leqq 1 \text { on } X, \quad \operatorname{Im} f\left(x_{0}\right)=0 \text { and }\|f\| \geqq K^{*} .
$$

Then $R e f$ is in $R e A$ and $>0$. By Lemma 2, then, $\log (R e f)$ also is in $R e A$, i.e. there is some $F$ in $A$ with $R e F=\log (R e f)$. Put now $V=\exp \left(\frac{1}{2} F\right)$. Then again $V$ is in $A$. Also $|V|^{2}=R e f$. Then $\max _{x}|V|=\|V\| \leqq 1$.

We now use the following identity, true for each complex $z$ :

$$
(\operatorname{Re} z)^{2}=\frac{1}{2}\left(\operatorname{Re} z^{2}+|z|^{2}\right) \text {. }
$$

Applying this to $V$ and using that $|V|^{2}=R e f$, we get

$$
(\operatorname{Re} V)^{2}=\operatorname{Re}\left(\frac{1}{2}\left(V^{2}+f\right)\right) \text {. }
$$

Clearly for each $h$ in $A$, we have $N(R e h) \geqq\|h\|-\left|\operatorname{Im} h\left(x_{0}\right)\right|$. Hence $N\left((R e V)^{2}\right) \geqq \frac{1}{2}\left(\left\|V^{2}+f\right\|-\left|\operatorname{Im} V^{2}\left(x_{0}\right)\right|\right) \geqq \frac{1}{2}\left(K^{*}-2\right)$, since $\|f\| \geqq K^{*}$ while $\left\|V^{2}\right\| \leqq 1$.

On the other hand, by Lemma 1 ,

$$
N\left((R e V)^{2}\right) \leqq K \cdot(N(R e V))^{2} \text { and } N((R e V)) \leqq 2\|V\| \leqq 2 \text {. }
$$

Since $K^{*}$ is arbitrary while $K$ is fixed, we have a contradiction. Thus Theorem $1^{\prime}$ is proved.

3. The general case. To deduce the result in the general case from Theorem 1', we use the following theorem of Bishop [1]. (See also [2].):

TheOREM. Let $A$ be any function algebra on $X$. Then there exists a collection $\Phi$ of closed, pairwise disjoint sets covering $X$ so that

(a) $f$ in $C(X)$ and $f \mid K$ in $A \mid K$ for every $K$ in $\Phi$ imply $f$ in $A$;

(b) $A \mid K$ is closed in $C(K)$ for each $K$ in $\Phi$.

(c) $A \mid K$ is antisymmetric on $K$ for each $K$ in $\Phi$.

Because of Bishop's theorem, one has the following method of reasoning: let $(P)$ be a property which has meaning for every function algebra $A$. Assume

(i) Whenever a given $A$ has property (P), then so does each restriction algebra $A \mid K$ for $K$ in $\Phi$, and

(ii) Whenever $A$ is antisymmetric on the space $X$ and $A$ has 
property $(P)$, then $X$ consists of a single point.

We then conclude, using the Theorem, that if $A$ is a function algebra on a space $X$ such that $A$ has property $(P)$, then $A=C(X)$. Thus, if $(P)$ is the property " $A$ is closed under complex conjugation", (i) and (ii) clearly hold, and one concludes the Stone-Weierstrass theorem.

If $(P)$ is the property " $R e A$ is a ring", then (i) also clearly holds, and that (ii) holds was the content of Theorem 1'. Thus we may conclude Theorem 1.

\section{REFERENCES}

1. E. Bishop, A generalization of the Stone-Weierstrass theorem, Pacific J. Math., 11, (1961), 777-783.

2. I. Glicksberg, Measures orthogonal to algebras and sets of antisymmetry, Trans. Amer. Math. Soc., 105 (1962), 415-435.

3. K. Hoffman and J. Wermer, A characterisation of $C(X)$ Pacific J. Math., 12 (1962), 941-944.

BROWN UNIVERSITY 


\section{PACIFIC JOURNAL OF MATHEMATICS}

\section{EDITORS}

RalPh S. Phillips

Stanford University

Stanford, California

M. G. Arsove

University of Washington

Seattle 5 , Washington
J. Dugundu

University of Southern California

Los Angeles 7, California

Lowell J. Paige

University of California

Los Angeles 24, California

\section{ASSOCIATE EDITORS}
E. F. BECKENBACH
D. DERRY
H. L. ROYDEN
E. G. STRAUS
T. M. CHERRY
M. OHTSUKA
E. SPANIER
F. WOLF

\section{SUPPORTING INSTITUTIONS}

\author{
UNIVERSITY OF BRITISH COLUMBIA \\ CALIFORNIA INSTITUTE OF TECHNOLOGY \\ UNIVERSITY OF CALIFORNIA \\ MONTANA STATE UNIVERSITY \\ UNIVERSITY OF NEVADA \\ NEW MEXICO STATE UNIVERSITY \\ OREGON STATE UNIVERSITY \\ UNIVERSITY OF OREGON \\ OSAKA UNIVERSITY \\ UNIVERSITY OF SOUTHERN CALIFORNIA
}

\author{
STANFORD UNIVERSITY \\ UNIVERSITY OF TOKYO \\ UNIVERSITY OF UTAH \\ WASHINGTON STATE UNIVERSITY \\ UNIVERSITY OF WASHINGTON \\ AMERICAN MATHEMATICAL SOCIETY \\ CALIFORNIA RESEARCH CORPORATION \\ SPACE TECHNOLOGY LABORATORIES \\ NAVAL ORDNANCE TEST STATION
}

Mathematical papers intended for publication in the Pacific Journal of Mathematrcs should be typewritten (double spaced), and the author should keep a complete copy. Manuscripts may be sent to any one of the four editors. All other communications to the editors should be addressed to the managing editor, L. J. Paige at the University of California, Los Angeles 24, California.

50 reprints per author of each article are furnished free of charge; additional copses may be obtained at cost in multiples of 50 .

The Pacific Journal of Mathematics is published quarterly, in March, June, September, and December. Effective with Volume 13 the price per volume (4 numbers) is $\$ 18.00$; single issues, $\$ 5.00$. Special price for current issues to individual faculty members of supporting institutions and to individual members of the American Mathematical Society: $\$ 8.00$ per volume; single issues $\$ 2.50$. Back numbers are available.

Subscriptions, orders for back numbers, and changes of address should be sent to Pacific Journal of Mathematics, 103 Highland Boulevard, Berkeley 8, California.

Printed at Kokusai Bunken Insatsusha (International Academic Printing Co., Ltd.), No. 6 , 2-chome, Fujimi-cho, Chiyoda-ku, Tokyo, Japan.

\section{PUBLISHED BY PACIFIC JOURNAL OF MATHEMATICS, A NON-PROFIT CORPORATION}

The Supporting Institutions listed above contribute to the cost of publication of this Journal, but they are not owners or publishers and have no responsibility for its content or policies. 


\section{Pacific Journal of Mathematics}

\section{Vol. 13, No. $4 \quad$ June, 1963}

Dallas O. Banks, Bounds for eigenvalues and generalized convexity ........... 1031

Jerrold William Bebernes, A subfunction approach to a boundary value problem for

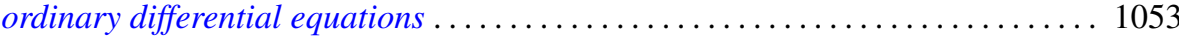

Woodrow Wilson Bledsoe and A. P. Morse, A topological measure construction . . . 1067

George Clements, Entropies of several sets of real valued functions . . . . . . . . . 1085

Sandra Barkdull Cleveland, Homomorphisms of non-commutative *-algebras . . . . . 1097

William John Andrew Culmer and William Ashton Harris, Convergent solutions of

ordinary linear homogeneous difference equations . . . . . . . . . . . . . . . 1111

Ralph DeMarr, Common fixed points for commuting contraction mappings . . . . . . 1139

James Robert Dorroh, Integral equations in normed abelian groups . . . . . . . . 1143

Adriano Mario Garsia, Entropy and singularity of infinite convolutions . . . . . . . 1159

J. J. Gergen, Francis G. Dressel and Wilbur Hallan Purcell, Jr., Convergence of extended Bernstein polynomials in the complex plane ................. 1171

Irving Leonard Glicksberg, A remark on analyticity of function algebras . . . . . . 1181

Charles John August Halberg, Jr., Semigroups of matrices defining linked operators

with different spectra ................................. 1187

Philip Hartman and Nelson Onuchic, On the asymptotic integration of ordinary

differential equations . . . . . . . . . . . . . . . . . . . . . . . . . . . . 1193

Isidore Heller, On a class of equivalent systems of linear inequalities . . . . . . . . . 1209

Joseph Hersch, The method of interior parallels applied to polygonal or multiply

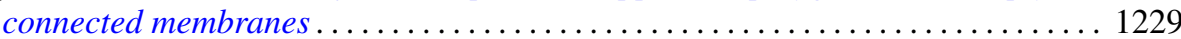

Hans F. Weinberger, An effectless cutting of a vibrating membrane . . . . . . . . . . 1239

Melvin F. Janowitz, Quantifiers and orthomodular lattices ....

Samuel Karlin and Albert Boris J. Novikoff, Generalized convex inequalities . .

Tilla Weinstein, Another conformal structure on immersed surfaces of negative

curvature.

Gregers Louis Krabbe, Spectral permanence of scalar operators

Shige Toshi Kuroda, Finite-dimensional perturbation and a representaion of

scattering operator.

Marvin David Marcus and Afton Herbert Cayford, Equality in certain

inequalities

Joseph Martin, A note on uncountably many disks .

Eugene Kay McLachlan, Extremal elements of the convex cone of semi-norms . . . . 1335

John W. Moon, An extension of Landau's theorem on tournaments . .

Louis Joel Mordell, On the integer solutions of $y(y+1)=x(x$

Kenneth Roy Mount, Some remarks on Fitting's invariants .....

Miroslav Novotný, Über Abbildungen von Mengen ............

Robert Dean Ryan, Conjugate functions in Orlicz spaces.

John Vincent Ryff, On the representation of doubly stochastic operators . . . . . . . . 1379

Donald Ray Sherbert, Banach algebras of Lipschitz functions .

James McLean Sloss, Reflection of biharmonic functions across analytic boundary

conditions with examples.

L. Bruce Treybig, Concerning homogeneity in totally ordered, connected topological space....

John Wermer, The space of real parts of a function algebra...

James Juei-Chin Yeh, Orthogonal developments of functionals and related theorems

in the Wiener space of functions of two variables......... 